\title{
Using Computer Microscopy Methods to Control the Microstructure of Malleable Cast Iron Product with Spherical Graphite*
}

\author{
Konstantin Makarenko ${ }^{[0000-0002-7195-0500]}$, Alexander Nikitin ${ }^{[0000-0003-1891-5033]}$, \\ Alexander Vdovin ${ }^{[0000-0002-6014-0043]}$, and Ekaterina Zentsova ${ }^{\text {[0000-0003-1513-3271] }}$ \\ Bryansk State Technical University, Bryansk, Russian Federation \\ makkon1@yandex.ru \\ zzzalexzzz95@gmail.com \\ vdovin.alexander.v@yandex.ru \\ kopilka.32@mail.ru
}

\begin{abstract}
The method of identification of objects on images of the microstructure of cast iron with spherical graphite of the correct shape with uniform distribution is presented. Morphological analysis techniques were used to identify shrinkage pores and graphite inclusions in microstructure images. Geometric features of the shape of graphite inclusions were used as methods for identifying graphite, in particular, particle size analysis, which is widely used to identify various objects in computer microscopy. The computer analysis of the image was performed with the program ImageJ. To determine the pores against the background of graphite inclusions, two characteristics were used - the shape and size of the objects themselves. The pores, presented on the image, differ from graphite inclusions by a complex, fractal border and comparatively large areas. For the visualization of the research results, the combination of the graphite part with the calculation and analytical part was used. Such presentation of the results is the most significant and allows to perform the most correct evaluation of the graphitized cast iron microstructure in accordance with GOST 3443-87.
\end{abstract}

Keywords: Computer Microscopy, Microstructure, Metallography, Image, Cast Iron, Graphite, Pores.

Copyright $(C 2020$ for this paper by its authors. Use permitted under Creative Commons License Attribution 4.0 International (CC BY 4.0).

* Publication financially supported by RFBR grant №20-01-00547 


\section{Introduction}

The modern methods of computer microscopy allow you with a high degree of adequacy, mathematically, to describe the main dimensional and topological characteristics of the structure of constructional materials. The data, obtained in the result of such analysis can be used for the description and construction of mathematical models, evaluating the relationship "structure-properties". Using the modern methods for processing large data arrays, accumulated in the course of numerous researches, it becomes possible to create the predictive models of managing the technology for obtaining products, in order to ensure the presence of the specified properties in them, directly from the cast state $[1,2]$.

The modern methods of the identification of graphitized cast iron structure use different approaches to identify dimensional and topological parameters of the structure. The significant influence on the properties of graphitized cast irons comes from such parameters as distribution and shape of graphite inclusions. These characteristics are difficult to describe objects and different researchers use different methods of their identification. For example, in the work [3], the method of the study of graphite phase distribution in the amount of cast iron is presented, it uses the most accurate technique of synchrotron mathematical tomography. The method allows you to visualize the distribution of the basic phases, particularly, graphite inclusions in the amount of cast iron. Such method, however, in spite of high adequacy of the obtained results, was not widely used due to the limited usage of this class research equipment in the world practice. Most frequently used methods of the study of dimensional and topological characteristics of cast irons are the methods of computer microscopy for structure images, obtained on modern digital optical microscopes [4-9]. It is connected with a wide introduction into the production of digital microscopes, allowing not only to perform photo- and video-fixation of the studied materials' structures, but also to describe mathematically the studied objects.

The purpose of this work is to develop the technique of identification for objects of the types of pores and gas inclusions for the development of the technology, managing cast iron structure and for the obtaining products with the specified properties from cast irons.

\section{The Technique of the Conducting Research}

As initial samples for the research, the cylindrical cast billets were taken, these pieces are used in the production of the samples, designed to identify the cast iron mechanical properties. Metallographic slots for the microscopic researches were obtained from the upper parts of the billets. That is why, in the structure of cast iron, except the graphite inclusions that are identified on the non-etched thin sections, there were the shrinkage pores. The initial image of the microstructure of the studied cast iron is presented in the Fig. 1.

To obtain the image of the cast iron microstructure, the digital complex, created on the base of the inverted metallographic microscope Leica DM IRM, was used. As it 
was mentioned above, the study of the cast iron microstructure was performed on the non-etched thin section.

On the microstructure image, there are two objects to be studied. The first one - the pores, representing internal cavities that break the continuity of the material. The object is referred to casting defects and is an undesirable artifact. The second object - the graphite inclusions that are an indispensable part of the ductile cast iron structure. The majority of mechanical properties of the product material depend on the graphite inclusions' shape, size and distribution.

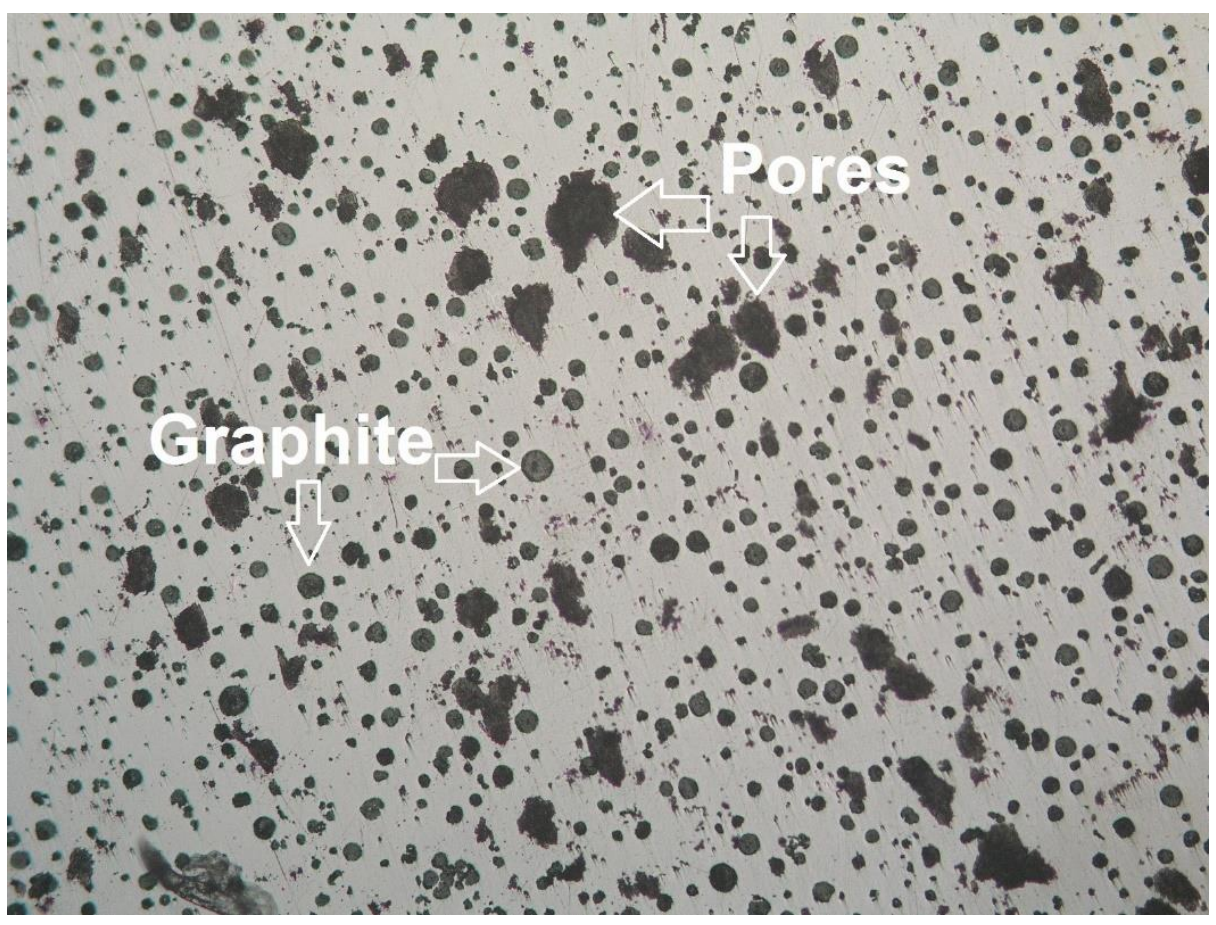

Fig. 1. The image of the initial microstructure of cast iron samples, $\times 100$ (non-etched)

In metallography there is a problem of identification of such objects. Very often, even experienced metallographs, not knowing the samples' prehistory, cannot identify pores and distinguish them on the studied thin section. The problem is compounded by the fact that the graphite inclusions' shape is a changeable and the main controlled parameter in graphitized cast irons. The ideal structure of ductile cast iron contains graphite inclusions of a globular (it is more correctly, spherical) shape. But any deviation in the modification technology and the chemical composition leads to degradation of the graphite phase morphology and it degenerates into a vermicular graphite shape. A perfunctory study of the structure, presented in the Fig. 1, may give the wrong idea and the pores can be identified in correctly as a degenerated, vermicular graphite shape.

Meanwhile, on the presented microstructure image, a number of features can be identified, helping to perform the correct identification of objects. Firstly, it is a colour 
scheme (or highlight the brightness level), the pores on the image have a darker (black) tint than a graphite phase, characterized by a grey," graphite" colour. This difference is due to the peculiarities of getting images in the optical reflecting metallographic microscope. When reflected from the pores, having a certain depth, the light beam is scattered, that is the light rays, having got in this area, do not return to the microscope lens, so the area containing the pores will be of a black colour. In the computer analysis of the image, using a grey palette with the brightness gradations, you can select such color range that will match the pores. As it follows from the previously presented explanation, its values will adjoin the values of completely black colour. Secondly, you can use the geometrical peculiarities of the graphite inclusions' shapes in ductile cast irons. For these purposes, you can use the granulometric analysis, widely applied for the identification of different objects in the computer microscopy. To identify the pores on the graphite inclusions' background, two features are used - directly a shape and sizes of the objects. The pores, presented on the image, differ from graphite inclusions by a complex, fractal border and comparatively large areas.

It was the second approach that was used in this work to identify the undesirable artifacts on the image of the ductile cast iron microstructure.

The computer analysis of the image was performed with the program ImageJ.

\section{The Research Results}

In this part, the separate stages of the analysis of the initial image of the ductile cast iron microstructure, made to identify the shrinkage pores on the graphite phase background, are presented. Taking into account the fact that the image quality was good, the noise elimination was not performed. That is why, the first stage of the image processing was the operation of the binarization. With this representation of the image, it can be easily analyzed on the basis of counting pixels, occupied by certain objects. The results of the image binarization are presented in the Fig. 2.

The following stage of the analysis included the segmentation of inclusions. The segmentation allows to identify different objects on the basis of different distinctive stereological and planar parameters. Given the fact that in ductile cast iron, in the thin section plane, the graphite inclusions are in the shape of a circle, their identification on the image simplifies. The Fig. 3 shows the results of selection of the graphite inclusions of a circular shape on the background of the pores of much larger sizes and more complex geometrical border morphology.

To identify an average area, occupied by the graphite phase, the previously segmented image was divided into four identical parts (Fig. 4). Within each separate part, the analysis of the area, occupied by graphite inclusions, to the area of the metal matrix, was performed. The results of the researches are presented in the Fig.5 and in the Fig. 6. 


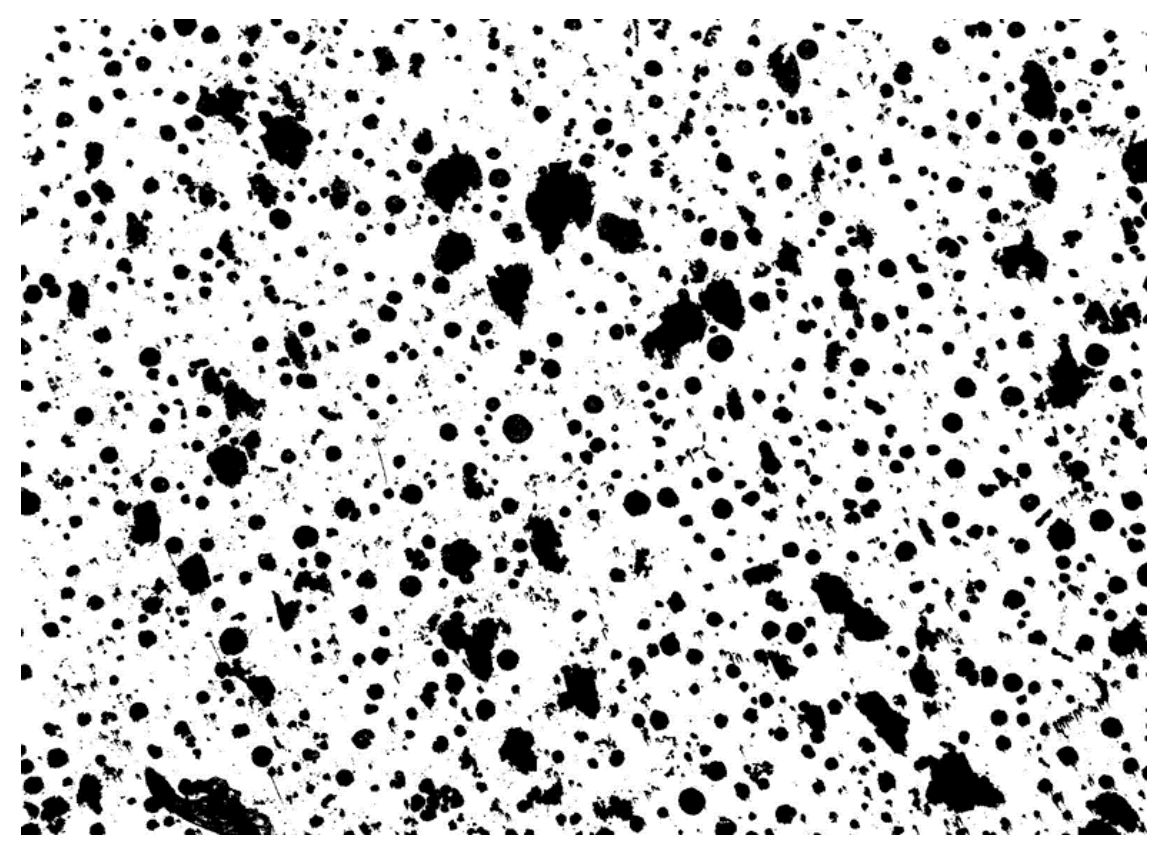

Fig. 2. The binary image of the studied cast iron microstructure

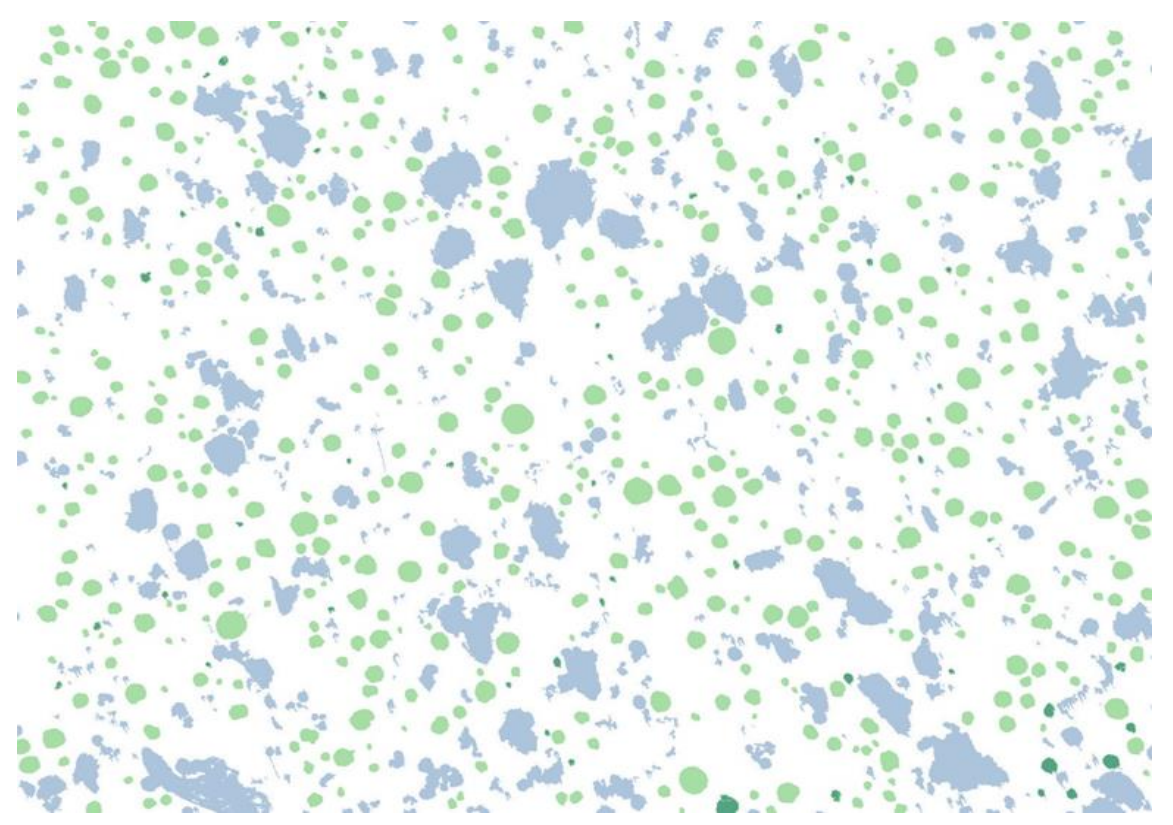

Fig. 3. The inclusions' segmentation of the graphite inclusions (green colour) and the shrinkage pores (lilac colour) 
6 K.Makarenko, A.Nikitin, A.Vdovin, E.Zentsova

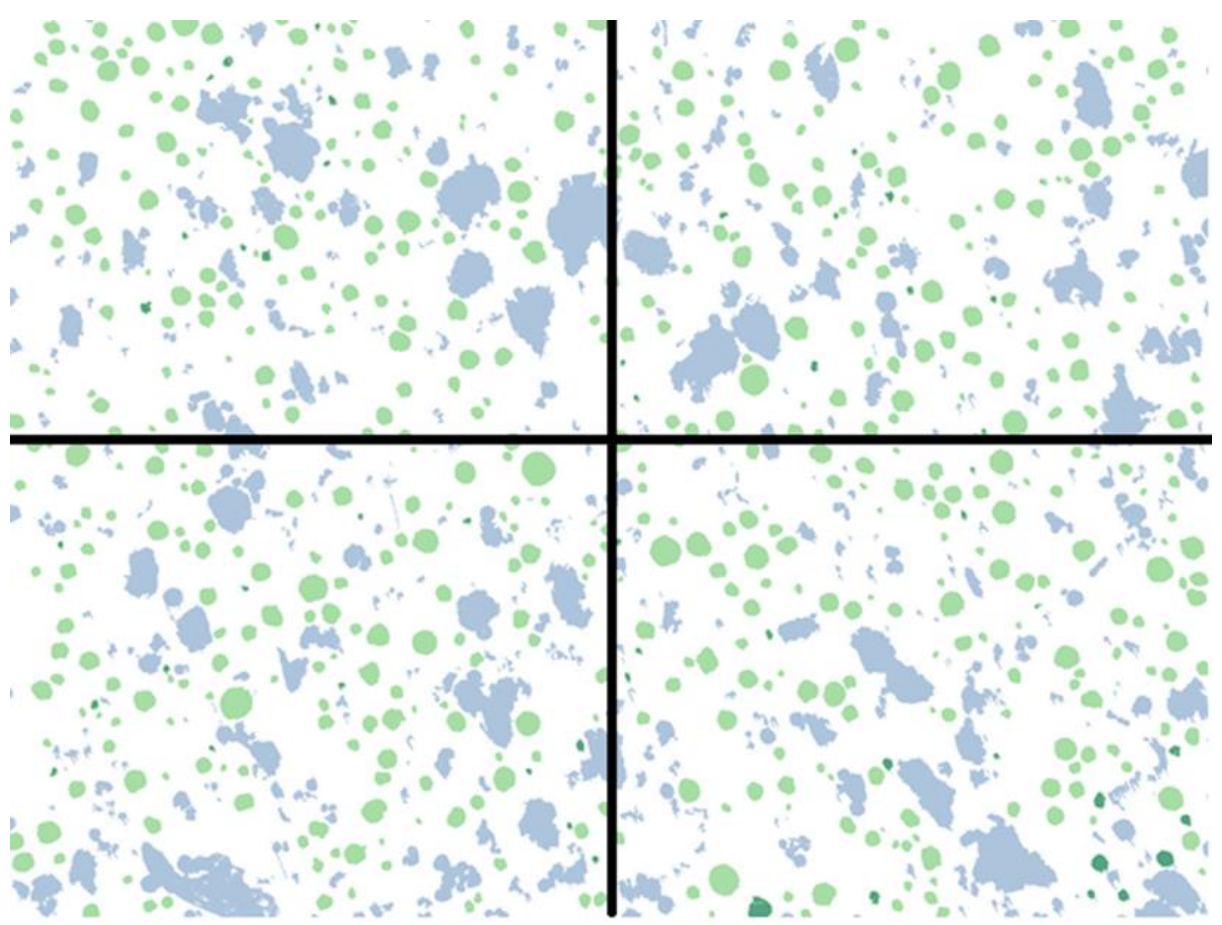

Fig. 4. The division of the image into four parts

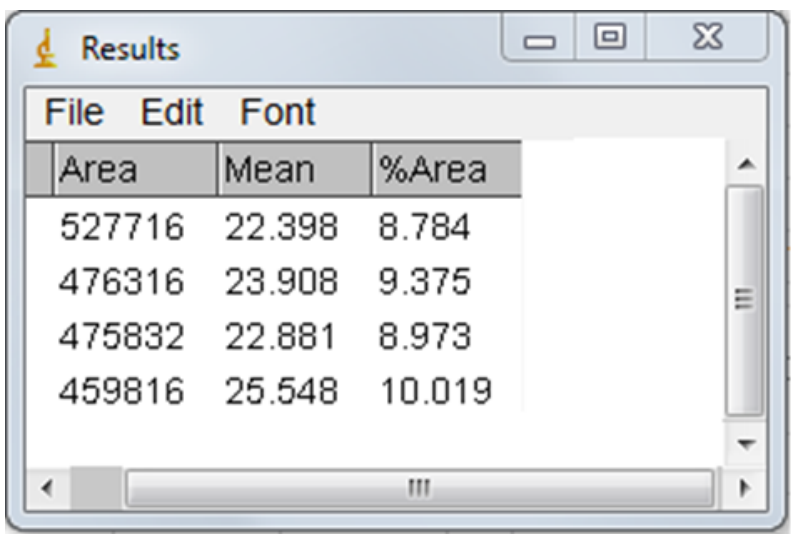

Fig. 5. The ratio of the area, occupied by graphite, to the total area of the matrix material

The analysis of the graphite phase distribution on separate sections of the microstructure image allowed to identify the normal distribution of graphite inclusions in ductile cast iron. The prevailing size of graphite inclusions for all parts of the image, in pixels is in the range from 300 to 700 units. 
At the final stage, the results of the identification of the dimensional and topological characteristics in the studied cast iron microstructure, were summarized. For the visualization of the research results, the combination of the graphite part with the calculation and analytical part was used (Fig. 7). Such presentation of the results is the most significant and allows to perform the most correct evaluation of the graphitized cast iron microstructure in accordance with GOST 3443-87.

\section{Conclusion}

The presented method of the analysis of the graphitized cast iron images is available for use only with the identification of the microstructure where the spherical graphite inclusions are prevailed. In case of the simultaneous presence of the spherical and vermicular inclusions in the cast iron structure, their identification becomes difficult. In this situation, it is necessary to use the method, based on the selecting the objects by brightness (colour).
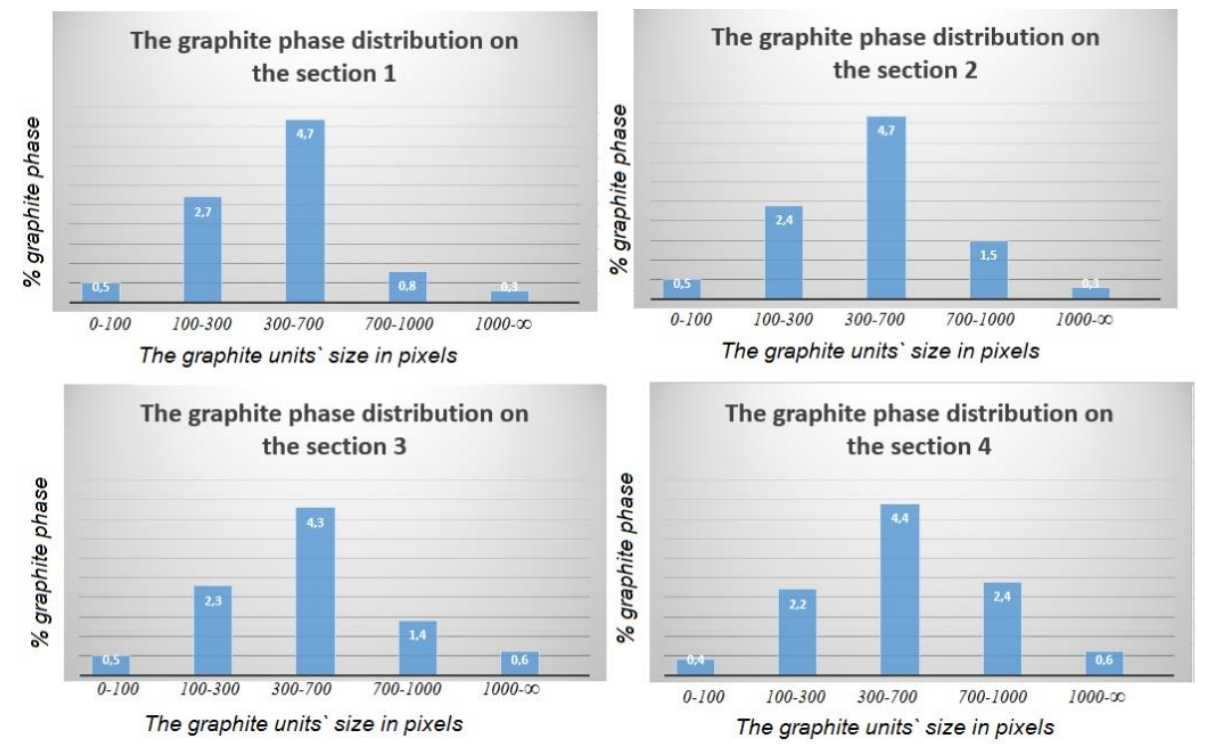

Fig. 6. The inclusions' distribution by sizes in four studied frequent images 


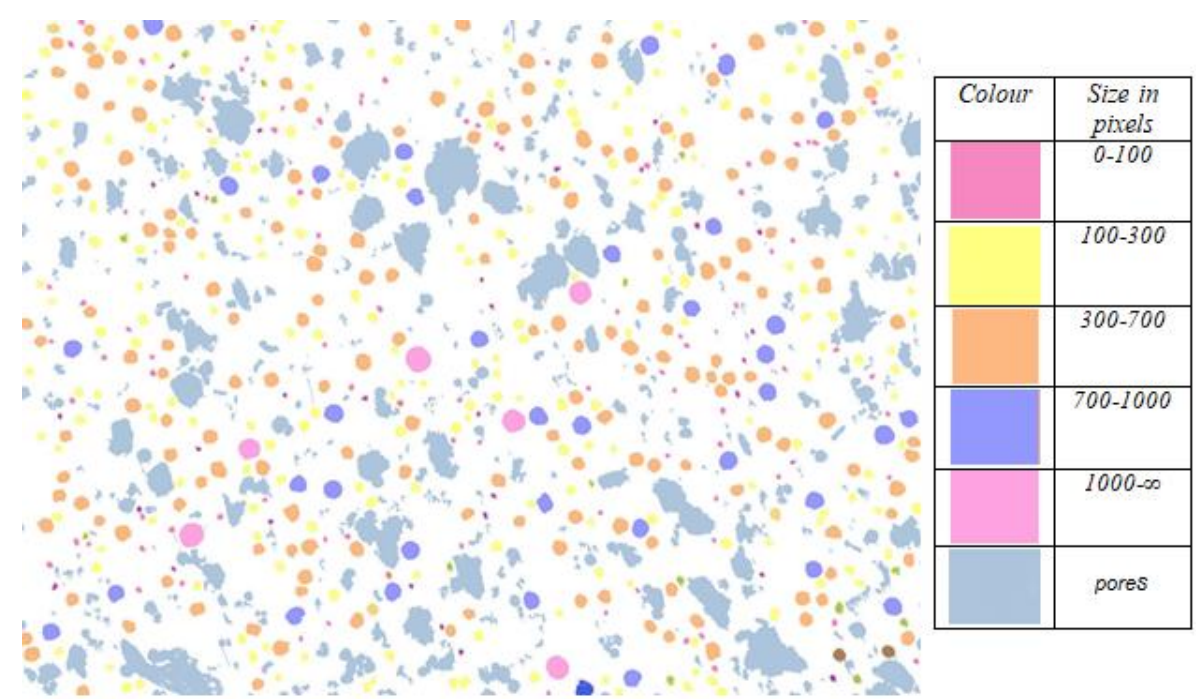

Fig. 7. The results of the analysis of the microstructure of the ductile cast iron sample with the selection of the graphite inclusions and the shrinkage pores

However, from our point of view, the best results of the objects' identification in the graphitized cast irons, you can obtain, using the integrated approach, combining two methods simultaneously

\section{References}

1. Panteleev V.G.: Computer Microscopy / V.G.Panteleev, O.V.Egorova, E.I.Klykova.-M.: Technosphera,2005.- p.304 (in Russ.).

2. Makarenko K.V.: Fractal Analysis of Morphological Parameters of the Structure Materials / K.V. Makarenko, A.A. Nikitin // CEUR Workshop Proceeding of the 9th International Conference on Computer Graphics and Vision (GraphiCon 2019). - Vol. 2485. - pp. 240243.

3. Azeem M., Bjerre M., Atwood R., Tiedje N., Lee P.: Synchrotron quantification of graphite nodule evolution during the solidification of cast iron. Acta Materialia. - 2018. - Vol. 155. - pp. $393-401$.

4. Iacoviello F., Iacoviello D., Cocco V., Santis A., D'Agostino L.: Classification of ductile cast iron specimens based on image analysis and support vector machine. XXIV Italian Group of Fracture Conference, 1 - 3 March 2017, Urbino, Italy. - Procedia Structural Integrity/ - 2017. - Vol. 3. - pp. $283-290$.

5. Sadato Hiratsuka, Hiroshi Horie, Toshinori Kowata, Katsumi Koike and Kazumichi Shimizu: Influence of Steel Scrap on Microstructure and Mechanical Properties of Spheroidal Graphite Cast Iron. Materials Transactions. - 2003. - Vol. 44, No. 7. - pp. 1419- 1424.

6. Mourad M., El-Hadad S., Ibrahim M., Nofal A. A.: Effect of Processing Parameters on the Mechanical Properties of Heavy Section Ductile Iron. Journal of Metallurgy. - 2015. - Article ID 931535. - $11 \mathrm{p}$. 
Using Computer Microscopy Methods to Control the Microstructure of Malleable... 9

7. Kiani-Rashid, A. R., Rounaghi S. A.: The New Methods of Graphite Nodules Detection in Ductile Cast Iron. Materials and Manufacturing Processes. - 2011. - Vol. 26. - pp. 242248.

8. Malage, A., Rege P., Rathod M.: Automatic Quantitative Analysis of Microstructure of Ductile Cast Iron using Digital Image Processing. Metallurgical Materials Engineering. 2015. - Vol. 21 (3). - pp. 155-165.

9. Morales-Hernández L.A., Herrera-Navarro A.M., Manriquez-Guerrero F., Peregrina-Barreto H., Terol-Villalobos I. R.: Size and Spatial Distributions Characterization of Graphite Nodules Based on Connectivity by Dilations. In: P. Soille, M. Pesaresi, and G.K. Ouzounis (Eds.): ISMM 2011, LNCS 6671. - pp. 461-471. 